https://doi.org/10.48009/1_iis_2005_190-196

\title{
FACTORS INFLUENCING THE ADOPTION OF E-LEARNING WEBSITES: AN EMPIRICAL STUDY
}

\author{
His-Peng Lu, National Taiwan University of Science and Technology, \\ hsipeng@cs.ntust.edu.tw \\ Su-Houn Liu, Chung Yuan Christian University, vandy@mis.cycu.edu.tw \\ Hsiu-Li Liao, National Taiwan University of Science and Technology, \\ wenlly.liao@msa.hinet.net
}

\begin{abstract}
The growth of the Internet has altered the way individuals learn. The recent advent of e-learning technology has made training, teaching and learning on the Internet more feasible. The new challenge for Internet education providers is attracting potential learners to use an e-learning website. This study develops a technology usage model for an e-learning website to generate several predictions about users' intentions and actual usage. The data obtained from our experiment strongly support our hypothesis. Findings indicate that perceptions of relative advantage and compatibility are significantly related to users' intentions; furthermore, users' intention is significantly related to actual usage of the e-learning website. This study also found that different acceptance models applied to learners who already had previous e-learning experience and those who had never previously used e-learning. For users with prior e-learning experiences, compatibility and result demonstrability have a significant, direct effect on use intentions. However, for users with no previous experience of using e-learning, compatibility, image and relative advantage have a significant, direct effect on user intentions. The study provides a more rounded, albeit partial, view of the online e-learning user and helps improve understanding of e-learning user acceptance behavior on the Web. Those interested in promoting web learning may find these results helpful in guiding their efforts.
\end{abstract}

Keywords: E-learning, perceived innovation characteristics, web learning, technology adoption

\section{INTRODUCTION}

The growth of the Internet has changed learning methods. The advent of e-learning technology has recently made training, teaching, and learning feasible on the Internet. Most colleges and universities in Taiwan already offer Internet-based coursework. With a PC connected to the web, web learning allows students to attend courses anywhere at any time.

Before the Internet era, a student who attended a distance learning course would have to receive his course materials by mail, and after completing his assignments, mail them back to be graded by a professor whom he would never meet. Today, however, learning on the web or web learning can be highly personal and interactive, allowing students to achieve an intimate out-of-classroom learning style. Nevertheless, the 2005 statistics of Market Intelligence Center in Taiwan [3] show that only $2.6 \%$ sampling subjects are willing to pay money for e-learning. Therefore, the new challenge for Internet education providers is how to attract potential learners to adopt their elearning websites. 
This study focuses on individual users' perceptions of target technology (web learning) as explanatory and predictive variables for their technology acceptance behavior. Although many other factors such as organizational characteristics and innovator characteristics can be considered influential to user acceptance [4], the perceived characteristics of an innovation such as web learning deserve our attention for several reasons. First, as discussed above, the construct is a recurring theme in technology adoption models. Second, since the various models theoretically include several perceptions, verifying whether all the perceptions indeed predict acceptance would be valuable, which might allow for the specification of more parsimonious models in which perceptions appear as constructs. Finally, the importance of perceptions should be investigated from a pragmatic perspective since they can be proactively influenced by management action [9].

Many studies have been conducted on users' acceptance behavior on specific technology. The study presented here is guided and motivated by two specific questions. First, can the innovation characteristics perceptions be used to predict individuals' intentions to learn in an e-learning website? Second, learners are already increasingly using web learning or other forms of elearning, raising an interesting research question whether learners experienced with e-learning systems have an acceptance model different from inexperienced learners.

\section{INNOVATION CHARACTERISTICS}

Innovation characteristics research considers that individuals' perceptions about the characteristics of an innovation significantly affect acceptance behavior. Such perceptions have been applied to explain both system usage [2,5] and usage intentions [7] and have thus persisted in the research literature.

According to Moore and Benbasat [5] the primary user perceptions that can help explain information technology (and other innovations) usage is comprised of seven constructs. The first construct, relative advantage, is similar to the concept of perceived usefulness of TAM [2]. The second construct, ease of use, which is also part of the TAM, is similar in definition to Rogers' [8] notion of complexity and encapsulates the degree to which a potential adopter considers usage of the target system to be relatively free of effort [2]. Moore and Benbasat [5] further identified five other perceived characteristics of innovations and empirically demonstrated their effects on technology and innovation adoption behavior. These characteristics are compatibility, image, result demonstrability, visibility and trialability. Moore and Benbasat applied Rogers' [8] notion of compatibility. Moore and Benbasat indicated that the image construct, subsumed by Rogers as part of relative advantage, can independently predict usage. Moore and Benbasat segregated Rogers' observability as comprising two separate constructs, result demonstrability and visibility. Finally, trialability measures the perception of potential adopters of an opportunity to experiment with the innovation prior to committing to its usage.

\section{The Research Model}

Figure 1 illustrates the Research Model empirically tested in this study. This model was constructed to answer the research questions raised earlier and is derived from the theory described in the previous section. In this model perceived innovation characteristics comprise 
seven user perceptions ease of use, relative advantage, compatibility, trialability, result demonstrability, visibility and image.

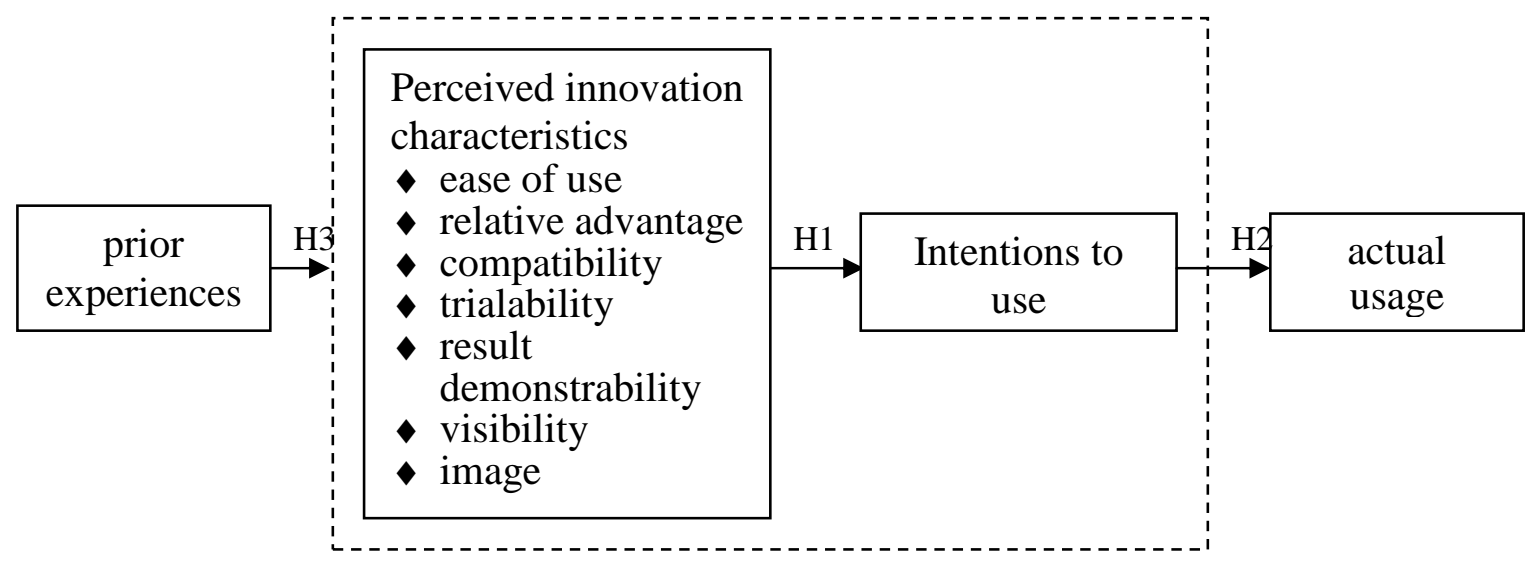

Figure 1. The Research Model

Based on a factor analysis of these items, Moore and Benbasat recommended a shortened version of these scales to include a total of 25 items, in which each scale consists of a minimum of two items statements regarding the e-learning website that respondents scored on a seven-point Likert-type scale with the end points being "strongly disagree" and "strongly agree." Actual usage was measured using four items similar to those in Davis [2]. As indicated by Davis, such self-reported measures are reasonable indicators of relative system usage. Table 1 shows the various constructs and the labels applied to them in the subsequent discussion.

Table 1. Research Variables and Definitions

Research variables

Ease of use

Relative advantage

Compatibility

Trialability

Result demonstrability

Visibility

Image

\section{Definition}

Degree to which an innovation is considered by the potential adopter as relatively easy to use and understandable then other compatible innovation

Degree to which an innovation is considered as superior to its predecessor

Degree to which an innovation is considered as compatible with existing values, beliefs, experiences and needs of adopters

Based on adopters' perceptions of the degree to which an innovation can be used on a trial basis before confirmation of the adoption must occur

Degree to which the results of using an innovation are perceived to be tangible

The perception of the actual visibility of the innovation itself as opposed to the visibility of outputs

The perception that using an innovation helps enhance or improve the social status of a potential adopter 


\section{Hypotheses}

A series of testable hypotheses were developed from the proposed research model, as shown below :

H1: The innovation characteristics perceptions of web learning are related to users' intentions to use the technology.

H1a: Perceptions of ease of use is positively associated with users' intentions about elearning website.

H1b: Perceptions of relative advantage is positively associated with users' intentions about an e-learning website.

H1c: Compatibility perceptions about using a web learning system are related to users' intentions.

H1d: The extent of trialability perceptions is related to users' intentions to use web learning.

H1e: The extent of result demonstrability is positively associated with users' intentions to learn on a website.

H1f: The perceptions of the actual visibility of the innovation are related to users' intentions to learn on a website.

H1g: The perceptions of the image are positively associated with users' intentions of an e-learning website.

H2: Users' intentions are related to their actual use of a web learning system.

H3: The effect of perceived innovation characteristics on users' intentions to use web learning is different between learners with or without previous e-learning experience.

\section{METHODOLOGY}

\section{The Sample}

To test the research model, an e-learning website was chosen as a representative of the innovation. This was considered to be appropriate precisely because of the emergent nature of the technology. A survey was conducted on students who were enrolled in a project management (PM) course at a comprehensive university. Digital materials related to conducting PM on Microsoft Project 2003 were developed on the e-learning website. Subjects received a one-hour, hand-on demonstration on using an e-Learning website before the course actually began. Subjects could use the e-learning web system through any Internet connection from anywhere at any time. After they finished the course, the students were asked to complete a survey. Completion of the survey was voluntary and could be done outside class. A total of 137 surveys were completed. The age range of the sample was 20-30 years old. Of the 137 respondents, 59 were females and 78 were males. Among these respondents, 41 did not have any previous elearning experiences.

\section{Measures}

Table 2 shows the number of items comprising each scale: the reliability reported by Moore and Benbasat [5] for the scale and Cronbach's alpha for scale reliability obtained for our sample. Reliability from our sample showed a reasonable level of reliability $(\alpha>0.70)$. Factor analysis also confirmed that the construct validity of the scales could be performed adequately. The factor 
loadings for all items exceeded 0.8 and indicated that the individual items also had discriminant validity.

Table 2. Scale Reliabilities

Scale

\begin{tabular}{l}
\hline Ease of use \\
Relative advantage \\
Compatibility \\
Trialability \\
Result demonstrability \\
Visibility \\
Image \\
Use intentions \\
Actual usage
\end{tabular}

\section{Number Moore and Benbasat Reliability}

4
5
3
2
4
2
3
3
2

0.84

0.90

0.86

0.71

0.79

0.83

0.79

\section{Reliability form Our Sample}
0.86
0.94
0.91
0.82
0.87
0.94
0.96
0.94
0.81

\section{RESULTS AND DISCUSSION}

Table 3 shows correlations for all research variables. Figure 2 summarizes the results of regression procedures used to inspect the relationships indicated by the research model. Although Table 3 indicates that most user perceptions are significantly correlated with each other, an examination of the variance inflation factors indicated that the multicollinearity was not significant [6]. Hence, residual analysis was also conducted to verify the assumptions underlying stepwise regression analysis. All assumptions were confirmed.

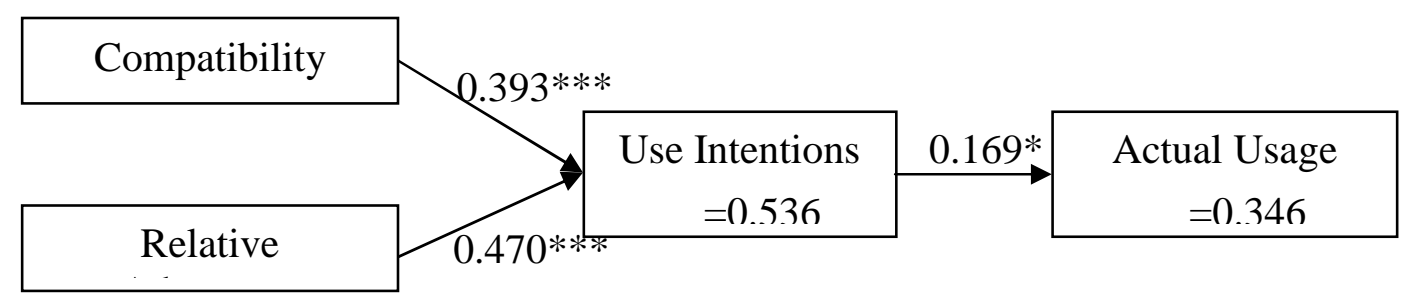

Figure 2. Technology Adoption Model of E-learning Website

The next step in the analysis was to test the significance of the individual terms in the model. These tests correspond to $\mathrm{H} 1-\mathrm{H} 2$. The null hypotheses tested, the $\mathrm{t}$ statistic, and significance level are illustrated in Figure 2, as is whether the hypothesis was supported (alpha $<0.05$ ).

Table 3. Pearson Correlation Coefficients

\begin{tabular}{llllll} 
& $\begin{array}{c}\text { Ease of Comp Image } \\
\text { Use }\end{array}$ & $\begin{array}{c}\text { Result Visibility } \\
\text { Dem }\end{array}$ & $\begin{array}{c}\text { Trial. } \\
\text { Rel } \\
\text { Adv }\end{array}$ & $\begin{array}{c}\text { Use Actual } \\
\text { Intent Usage }\end{array}$ \\
\hline Ease of use & 1.000 & & & \\
\hline Compatibility & $0.635^{* * *} 1.000$ & & & \\
\hline Image & $0.303^{* * *} 0.429^{* * *} 1.000$ & & & \\
\hline
\end{tabular}


Result

Demonstrability $0.459 * * * 0.335 * * * 0.346 * * * 1.000$

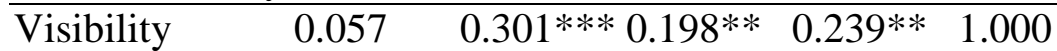

$\begin{array}{lll}\text { Trialability } 0.406 * * * 0.496 * * * 0.136 & 0.402 * * * 0.287 * * * & 1.000\end{array}$

Relative

Advantage

$$
0.525 * * * 0.434 * * * 0.268 * * * 0.534 * * * 0.241 * * * 0.531 * * * 1.000
$$

\begin{tabular}{llll}
\hline Use intentions & $0.465 * * * 0.598 * * * 0.339 * * * 0.470 * * * 0.154$ & $0.457 * * * 0.641 * * * 1.000$
\end{tabular}

\begin{tabular}{lllllllll}
\hline Actual usage & -0.244 & -0.033 & -0.054 & 0.000 & 0.040 & -0.070 & 0.003 & $0.169 * 1.000$ \\
\hline
\end{tabular}

Both hypotheses about relative advantage $(\mathrm{H} 1 \mathrm{~b})$ and compatibility $(\mathrm{H} 1 \mathrm{c})$ were supported, while those related to ease of use (H1a), trialability (H1d), result demonstrability (H1e), visibility (H1f) and image (H1g) were not supported.

Figures 3 and 4 graphically illustrate the significant relationships found in our study. For users with prior experience of using e-learning, compatibility and result demonstrability significantly and directly influence the intention to use. However, for users with no previous experience using e-learning websites, compatibility, image, and relative advantage had a significant, direct effect on intention to use. For those with and without e-learning experience, our study shows the impact of perceived innovation characteristics on intentions to use e-learning website were different. The hypotheses about users' prior experience $(\mathrm{H} 3)$ are thus supported.

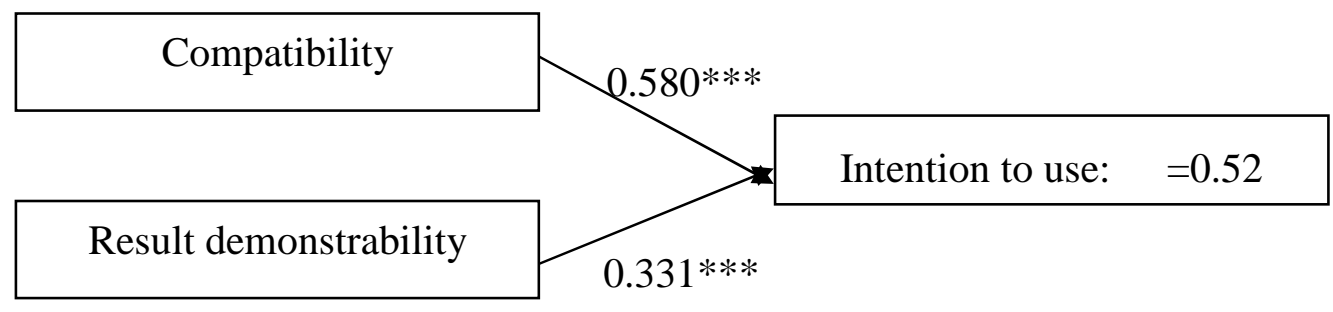

Figure 3. Technology Adoption Model For Users With Prior Experience Using E-Learning

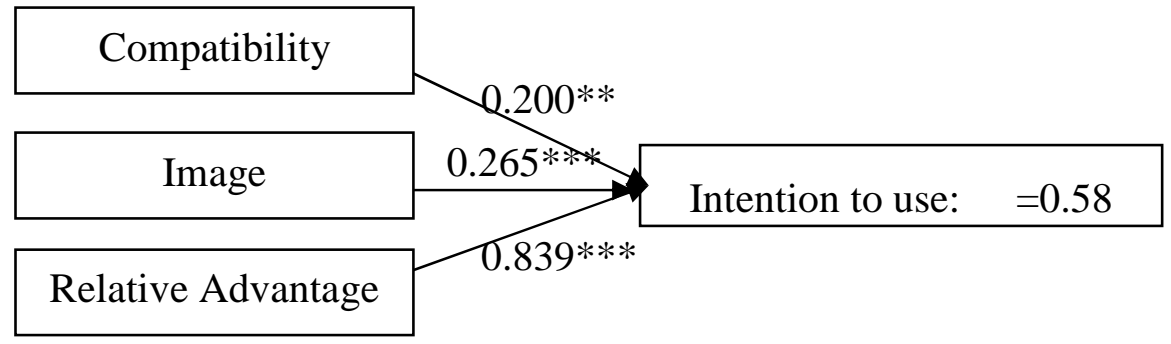

Figure 4. Technology Adoption Model For Users Without Prior Experience Using E-Learning 


\section{CONCLUSIONS AND MANAGERIAL RECOMMENDATIONS}

The analytical results of our investigation indicate a relationship between user perceptions of the characteristics of web learning and their intention to use the technology. More specifically, users' perceptions of the relative advantage and compatibility of e-learning websites exhibit significant relationships with their adoption intentions. The analytical results are generally consistent with prior research. Relative advantage and compatibility have received the most consistent support as factors that influence adoption and usage of an innovation [8].

Notably, examination of the relative strengths of the associations between the individual independent variables and adoption intention clearly indicate that perceived relative advantage and compatibility can explain much of the variation in adoption intention [1]. In other words, for web-learning learners, the perceptions of the relative advantage and compatibility of web learning are better predictors than other perception constructs.

When individuals have more experience with e-learning, the impact of perceived innovation characteristics on intentions to use web learning are different from that of inexperienced learners. Information obtained from experience over a period of time undoubtedly has the potential to modify future intentions of using web learning. Therefore, experience gained over time has potential implications for the technology usage model and future research should be conducted in this area. In this study, previous e-learning experiences, compatibility and result demonstrability have a significant, direct effect on use intentions. However, for users with no previous experience of using e-learning, compatibility, image and relative advantage have a significant, direct effect on user intentions.

\section{REFERENCES}

1. Van Slyke, C, Lou, H, \& Day, J. (2002). The impact of perceived innovation characteristics on intention to use groupware, Information Resources Management Journal, 15(1), 5-12.

2. Davis, F. D. (1993). User Acceptance of Information Technology: System Characteristics, User Perceptions and Behavioral Impacts, International Journal of Man-Machine Studies, 38(3), 475-487.

3. Hua Yi Chen, and Shu Lin Zhou (2005). The 2005 analysis of user behavior on Internet in Taiwan, Market Intelligence Center, 5-6.

4. Kwon, T., \& Zmud, R. (1987). Unifying the Fragmented Models of Information Systems Implementation (pp. 227-251). In Borland \& Hirschheim (Eds.), Critical Issues in Information Systems, New York: John Wiley.

5. Moore, G. C. \& Benbasat, I. (1991). Development of an instrument to measure the perceptions of adopting an information technology innovation, Information Systems, 2(3), 192-222.

6. Neter, J., Wasserman, W., \& dc Kutner, M. H., (1985). Applied linear statistical models. Homewood, IL: Irwin.

7. Agarwal, R \& Prasad, J. (1997). The role of innovation characteristics and perceived voluntariness in the acceptance of information technologies, Decision Sciences, 28(3), 557582.

8. Rogers, E. M. (1983). Diffusion of innovations, New York: The Free Press.

9. Wynekoop, J. L., Senn, J. A., \& Conger, S. A., (1992). The implementation of CASE tools: An innovation diffusion approach. 